\title{
受動歩行の脚切換え現象に関する実験的研究*
}

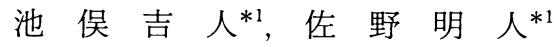 \\ 久世雅 人 $^{* 2}$, 藤 本 英 雄*1

\section{An Experimental Study for Leg-Exchange Phenomenon of Passive Walking}

\author{
Yoshito IKEMATA*4, Akihito SANO, \\ Masato KUZE and Hideo FUJIMOTO \\ ${ }^{* 4}$ Graduate School of Engineering, Nagoya Institute of Technology, \\ Gokiso-cho, Syowa-ku, Nagoya-shi, Aichi, 466-8555 Japan
}

\begin{abstract}
A passive walker can walk down shallow slope in a natural gait and can exhibit a stable limit cycle. In our earlier work, we have demonstrated the physical structure which forms the fixed point and the mechanism of its stability. A collision phenomenon is essential to the leg-exchange which is one of the important factors determined the fixed point. In general, the collision is undesirable because it causes troubles of precision sensors and instruments. In many studies, the leg-exchange is modeled by some assumptions and the validity of that is not sufficiently evaluated. In this study, the general model is qualitatively and quantitatively evaluated by the experiments. By observing actual collision phenomenon through the high-speed camera, we realized that the legs are not instantaneously exchanged and the loss of angular momentum is caused by the impact force during the collision. Based on this fact, the accurate modified leg-exchange model is proposed.
\end{abstract}

Key Words : Legged Locomotion, Passive Walking, Leg-exchange, Collision, Modeling

\section{1. 緒言}

受動歩行(1)では, 脚のダイナミクスと環境との相互 作用のみによって歩容が生成される。受動歩行は一種 の力学現象と捉えることができ, 人はその力学的原理 を巧く利用して歩いているものと考えられる。このた め, 受動歩行は歩行ロボットの制御や歩行メカニズム の本質を理解するうえで重要な研究対象である(2). 最 近では，受動歩行をべースとした歩行ロボットが開発 され，エネルギー効率の高い歩行が実現されてい $る^{(3)}$.

歩行は, 非線形な脚の振り運動(連続ダイナミクス) および脚の切換え現象 (離散事象) から成る。この一種 のハイブリッドシステムから周期的な運動が生成され る. 受動歩行では, 安定したリミットサイクル(閉軌 道)が存在するという重要な特徵を持つ. 状態がこの リミットサイクル上を遷移する限り, 歩行の安定性は 保証される。著者らは, 受動歩行の平衡点(リミット サイクルの一断面の点)の力学的構造ならびにその安

* 原稿受付 2005 年 9 月 8 日.

*1 正員, 名古屋工業大学大学院工学研究科 (更 466-8555 名古 屋市昭和区御器所町).

*2 名古屋工業大学大学院工学研究科.

E-mail : ikemata@ vier.mech.nitech.ac.jp
定化構造を明らかにした ${ }^{(4)}$. なお，この平衡点は，工 ネルギーバランス, 脚の振り運動および脚の切換え現 象が絡む力学的構造の中から生成される.

一般的に, 着地時の床面との衝突はセンサの障害や 機器の振動などを引き起こすため, 望ましくない現象 と捉えられ, 種々の衝撃緩和手段がとられている(5). しかし, この衝突現象は, 平衡点を決定する一つの重 要な要素である脚切換えには不可欠である。これま で，ある仮定の基で脚の切換え現象がモデル化されて きたが(1)(4)(6) (11), その妥当性について十分な評価がな されてこなかった。そこで, 本研究では受動歩行機を 模擬した簡単な実験機を用いて, 一般的な脚切換えモ デルを定性的・定量的に評価したうえで, 実際の衝突 現象の解析から,より厳密な脚切換えモデルを導出す ることを目的とする。

2 章では, 一般的な脚切換えモデルの導出および簡 単化を行う． 3 章では，実機を用いた実験から一般的 な脚切換えモデルを評価する４章では，観察された 衝突現象を解析し, より㛜密な修正モデルを導出して その妥当性を評価する.

\section{2. 脚切換えモデル}

$2 \cdot 1$ 仮定と導出 コンパス形の受動歩行モデル 
を図 1 に示す。lは脚の長さである。また, 腰と足先 のみに質量を持ち, それぞれ $M$ と $m$ で表す。 $\gamma$ はス ロープ角度, $g$ は重力加速度を表す。また, $\theta$ および 中は，それぞれ支持脚および遊脚の角度である。ただ

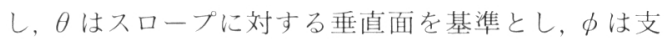
持脚を基準とする。なお, 図 1 に示す角度の向きを正

\section{とした。}

遊脚足先と床面との衝突によって, 支持脚と遊脚の 切換え現象が生じる. 受動歩行の研究では, 次のよう な仮定を扔いて, 脚切換えがモデル化される(1)(4)(6) (11).

（1）遊脚足先と床面との衝突は, 完全非弾性衝突 である。

（2）脚の切換えは瞬間的に行われ，支持脚は床面 から離れ遊脚となる.

上記の仮定が成り立つ場合, 脚切換え (着地) 前後に おいて, 腰まわりの支持脚の角運動量ならでに遊脚足 先まわりの全角運動量が保存されるものとする(12). これらの角運動量の保存則から, 次のような関係式が 得られる。

$$
\boldsymbol{Q}^{+}(\alpha) \dot{\boldsymbol{\theta}}^{+}=\boldsymbol{Q}^{-}(\alpha) \dot{\boldsymbol{\theta}}^{-}
$$

ただし，

$\boldsymbol{Q}^{+}(\alpha)$

$=\left[\begin{array}{cc}m l^{2}(1-\cos \alpha) & -m l^{2} \\ 2 m l^{2}(1-\cos \alpha)+M l^{2} & -m l^{2}(1-\cos \alpha)\end{array}\right]$

$\boldsymbol{Q}^{-}(\alpha)=\left[\begin{array}{cc}0 & 0 \\ M l^{2} \cos \alpha & 0\end{array}\right]$

ここで, $\boldsymbol{\theta}\left(=[\theta, \phi]^{T}\right)$ は脚の角度ベクトルを表す。ま た, 一は脚切換え直前の状態, + 汁切換え直後の状態 を示す。 $\alpha$ は着地時の股角度 $(\alpha>0)$ であり, $\alpha=$ $-2 \theta^{+}=2 \theta^{-}=-\phi^{+}=\phi^{-}$の関係式が成り立つ. 式 (1) から脚切換え直後の角速度べクトル $\dot{\theta}^{+}$は, 次の ように導出される。

$$
\dot{\boldsymbol{\theta}}^{+}=\left[\boldsymbol{Q}^{+}(\alpha)\right]^{-1} \boldsymbol{Q}^{-}(\alpha) \dot{\boldsymbol{\theta}}^{-}=\boldsymbol{H}(\alpha) \dot{\boldsymbol{\theta}}^{-}
$$

$$
\text { ただし, }
$$

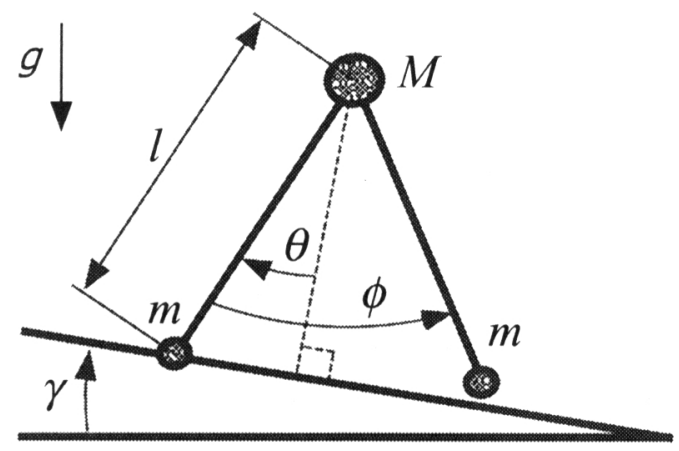

Fig. 1 Compass-like biped model

$$
\boldsymbol{H}(\alpha)=\left[\begin{array}{cc}
\frac{M \cos \alpha}{M+m \sin ^{2} \alpha} & 0 \\
\frac{M(1-\cos \alpha) \cos \alpha}{M+m \sin ^{2} \alpha} & 0
\end{array}\right]
$$

$2 \cdot 2$ 簡単化と特徵本研究では, 解析を容易に するために, 腰の質量 $M$ が足先の質量 $m$ に比べて十 分大きい $(M \gg m)$ ものとした。このモデルは, Simplest walking model と呼ばれ, 最も簡単な歩行モデ ルである(7). 歩行のクラスは限定されるものの, 本モ デルでも安定したリミットサイクルが存在する.

$M \gg m$ であることから $m / M \approx 0$ とみなせるので, 脚切換え式 $(2)$ は次のように簡単化できる.

$$
\left[\begin{array}{l}
\dot{\theta}^{+} \\
\dot{\phi}^{+}
\end{array}\right]=\left[\begin{array}{cc}
\cos \alpha & 0 \\
(1-\cos \alpha) \cos \alpha & 0
\end{array}\right]\left[\begin{array}{l}
\dot{\theta}^{-} \\
\dot{\phi}^{-}
\end{array}\right]
$$

行列式 ( 3 ) から, 切換え直後の支持脚の角速度は次の ようになる。

$$
\dot{\theta}^{+}=\cos \alpha \dot{\theta}^{-}=e \dot{\theta}^{-}
$$

本研究では $e$ を損失係数と呼ぶことにする。なお，衝 突におけるエネルギー残存率は, 次に示すように $e^{2}$ に一致する。

$$
\frac{\frac{1}{2} M l^{2} \dot{\theta}^{+2}}{\frac{1}{2} M l^{2} \dot{\theta}^{-2}}=\frac{e^{2} \dot{\theta}^{-2}}{\dot{\theta}^{-2}}=e^{2}
$$

式(4)からわかるように, 損失係数 $e$ は支持脚の角速 度 $\dot{\theta}^{-}$抢よびスロープ角度 $\gamma$ には依存せず, 着地時の 股角度 $\alpha$ みによって決まる。

\section{3. 実 験 的 検 証}

$3 \cdot 1$ 実験機および計測方法本研究では, 損失 係数 $e$ が股角度 $\alpha$ の)に依存することを実験的に確 認し,さらに脚切換え式 (4)の妥当性を定量的に評価 する。損失係数は $e=\dot{\theta}^{+} / \dot{\theta}^{-}$であるから, 着地前後の 支持脚の角速度を求めることになる(遊脚の動きは関 係ない)。そこで, 検証に適した実験機として, 四 2 に 示すような脚を腰部分で固定した実験機を用いる。こ れは,コンパス形の受動歩行機党一定の股角度で衝突 させることになる。

実験機の諸元を表 1 に示す。腰と足先はカツラ材を 用い, 脚は軽く剛性の高い炭素棒を用いた。なお，腰 の質量を足先・脚の質量よりも十分に大きくするため に, 腰の中心部分に真ちゅう製の円柱を埋め込んだ. 一方, 床面は厚さ $15 \mathrm{~mm}$ のラワン合板を用いた。衝 突時の合板のたわみ抢よび振動を防止するために, 30 $\times 30 \mathrm{~mm}$ の L 字アングルを裏打ちした，また，足先 と床面の滑りを抑えるために，合板の表面に厚さ1 $\mathrm{mm}$ の合成ゴムを貼り付けた. 
本実験では，遊脚足先を設定した高さから床面に衝 突させた。なお, 実験機が後方に倒れてしまう場合は, 支持脚を重力方向にまっすぐにした状態から腰に水平 力を加えて初期速度を与えた。計測方法に関しては, 両方の足先と腰の中心に直径 $4 \mathrm{~mm}$ のマーカを付け, 高速度力メラ (Photron 製: Fastcam-512 PCI 32 K) を用いて,これら三つのマーカを同時に撮影した。撮 影した脚切換えのようすを図 3 に示す。四 3 からわか るように, 遊脚足先が床面と衝突することによって支 持脚と遊脚が切換わる。なお，フレームサイズは 512 $\times 512$ pixels，撮影速度は $1000 \mathrm{frame} / \mathrm{s}$ である。

得られた画像からマーカの中心の位置座標を抽出

Table 1 Values of parameter of machine

\begin{tabular}{|c|r||c|r|}
\hline \multicolumn{2}{|c||}{ Length [cm] } & \multicolumn{2}{c|}{ Mass [g] } \\
\hline \hline$l$ & 32.0 & $M$ & 444 \\
\hline$W$ & 6.0 & $m$ & 9 \\
\hline$w$ & 5.0 & $m_{L}$ & 10 \\
\hline$\phi D$ & 6.0 & & \\
\hline$\phi d$ & 2.0 & \multicolumn{2}{|}{} \\
\hline$\phi d_{L}$ & 0.6 & \multicolumn{2}{|}{} \\
\hline
\end{tabular}

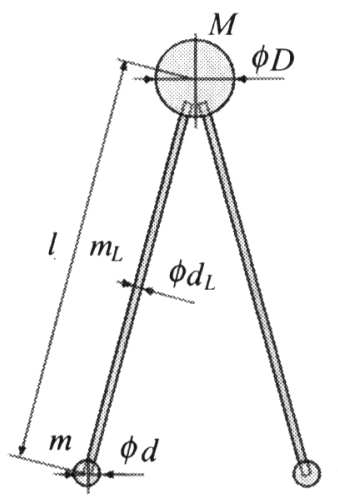

Sagittal plane

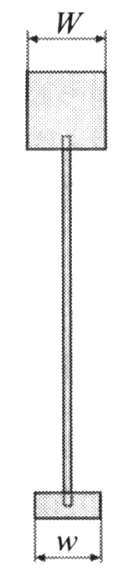

Lateral plane
Fig. 2 Experimental machine
し, 各マ一力の位置座標から支持脚の角度 $\theta$ を算出し た. 着地前後の微小時間では角度 $\theta$ の時間変化はほ ぼ線形となるため，その傾きから角速度 $\dot{\theta}$ を算出し た。

$3 \cdot 2$ 評価結果 まず, 股角度 $\alpha$ を $29.7 \mathrm{deg}$, ス ロープ角度 $\gamma$ を $0 \operatorname{deg}$ に設定し, 着地前後の支持脚の 角速度 $\dot{\theta}^{-}$を変えた場合の実験を行った。図4(a)に 実験結果を示す。横軸は角速度 $\dot{\theta}^{-}$, 縦軸は損失係数 eである。図 $4(\mathrm{a})$ からわかるように, 支持脚の角速 度 $\dot{\theta}^{-}$の值によらず, 損失係数 $e$ はほぼ一定 $(e=0.72$ $\pm 0.03)$ となった。また， $\gamma$ を $3 \mathrm{deg}$ に変更し同様な 実験を行った結果, $e=0.73 \pm 0.03$ となった。 以上の ことから, 損失係数 $e$ は, 支持脚の角速度 $\dot{\theta}^{-}$および スロープ角度 $\gamma$ には依存しないといえる。

次に， $\gamma$ を $0 \operatorname{deg}$ に固定し，股角度 $\alpha$ を変えた場合 の実験を行った。 $\alpha$ は脚構造および足先の滑りを考慮 して, $15 \mathrm{deg}$ から $35 \mathrm{deg}$ の範囲に7 通り設定した。 図 4 ( b ) に実験結果を示す。横軸は股角度 $\alpha$, 緃軸は 損失係数 $e$ である. 各股角度に対して 7 回の実験を 行い, その平均值および標準偏差を示した。なお, $e$ の解析値 [式(4)］を図中に併記した。四 4(b)から わかるように, 損失係数は着地時の股角度に依存して おり, 股角度が増大すると減少する特徵を持つことが 実験的に確かめられた。しかし, 実験值と解析值の間 には誤差が見られ，股角度が大きくなるにつれてその 差が大きくなる傾向にある.

以上のことから，2 章で示した脚切換えモデルは定 性的には合っているが, 定量的には問題がある。

\section{4. 厳密な脚切換えモデル}

$4 \cdot 1$ 実際の衝突現象 $3 \cdot 2$ 節で示した定量的な モデル化誤差は，モデル化に際して導入した二つの仮 定によるものだと考え, 実際の衝突現象をより詳細に 観察することにした。具体的には, 高速度カメラのフ レームサイズを $512 \times 128$ pixels, 撮影速度を 8000

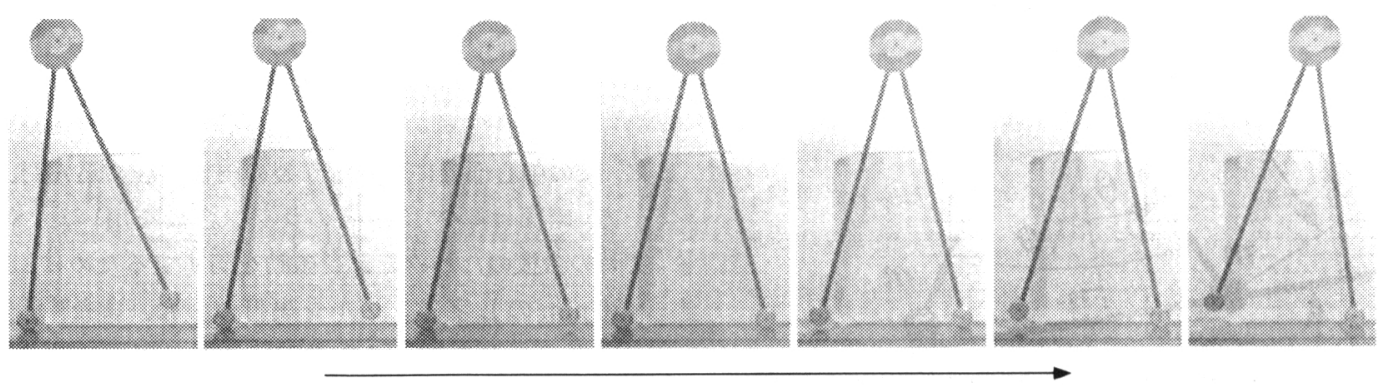

Fig. 3 Leg-exchange phenomenon 


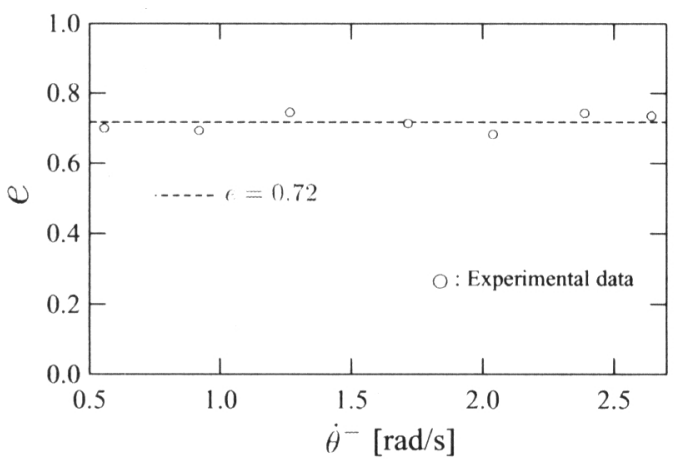

(a) Angular velocity of support leg $\dot{\theta}$

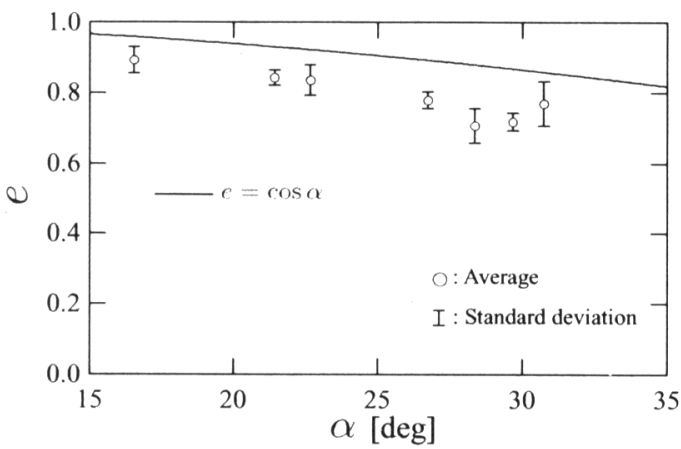

(b) Inter-leg angle $\alpha$

Fig. 4 Variation of loss coefficient $e$

frame/s に設定して床面付近を撮影した。

図 5 は股角度 $\alpha$ を $22.9 \mathrm{deg}$ とし, 遊脚足先を 20 $\mathrm{mm}$ の高さから床面に衝突させたときの連続写真で ある。図 5 からわかるように, 遊脚足先が床面に着地 してから支持脚が床面から完全に離れるまでに, 約 4 ms の時間がかかっている.したがって, $2 \cdot 1$ 節で述 ベた仮定のように脚の切換えは瞬間的には行われてお らず, 実際は次のように脚の切換えが行われていると 考えることができる。

（1）遊脚足先と床面との衝突は弾性衝突(完全非 弾性衝突を含む)である。ただし，跳㸚返りは微小で ある。

（2）脚の切換えには微小時間がかかり，その間, 支持脚足先まわりに衝突の衝撃によるトルクが発生 し, 角運動量が損失する.

$4 \cdot 2$ 角運動量の損失 本節では, $4 \cdot 1$ 節で述べた 実際の現象に基づき, 角運動量に関する式を導出す る.まず, 衝突(両脚が着地)している微小時間を $\Delta t_{d}$ とする.戝 6 に示すように, 衝突の衝撃によって遊脚 足先に衝撃力 $F_{d y}(y$ 方向成分) が発生する。このとき,

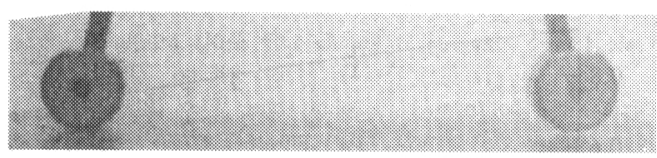

$0[\mathrm{~ms}]$

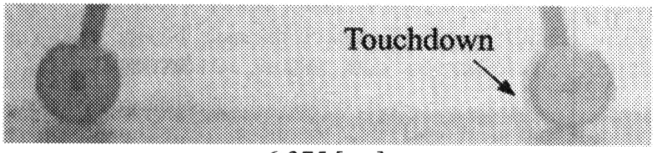

$6.375[\mathrm{~ms}]$

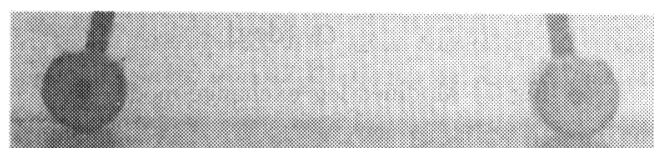

$8.125[\mathrm{~ms}]$

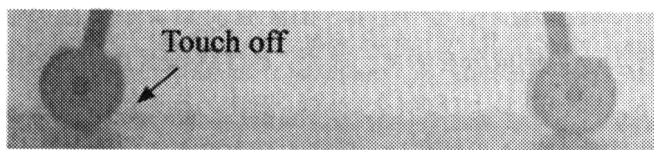

$10.125[\mathrm{~ms}]$

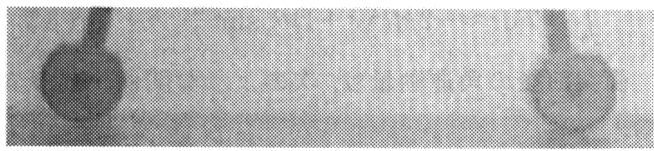

$14.375[\mathrm{~ms}]$

Fig. 5 Collision phenomenon

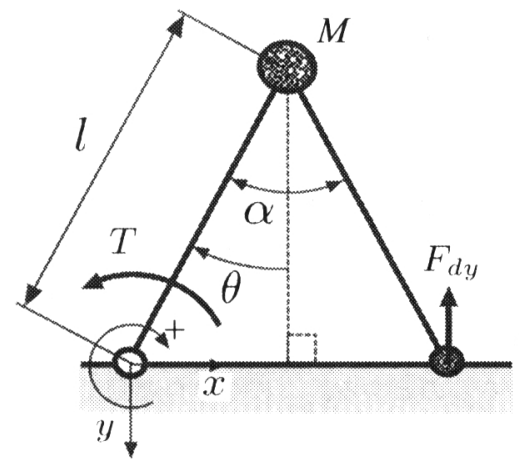

Fig. 6 Model of collision phenomenon

支持脚足先まわりに発生するトルク $T$ の総和は, 次 のように表すことができる。

$$
\int_{0}^{\Delta t_{d}} T \mathrm{~d} t \approx 2 \bar{F}_{d y} \Delta t_{d} l \sin \frac{\alpha}{2}
$$

ここで， $\bar{F}_{d y}$ は $F_{d y}$ の平均值を表す。また，衝突にお

ける運動量保存則と跳返り式から次式が導かれる.

$$
\begin{aligned}
\bar{F}_{d y} \Delta t_{d} & =M\left(v_{d y}^{+}-v_{d y}^{-}\right) \\
& =-M(c+1) v_{d y}^{-} \\
& =-M l(c+1) \dot{\theta}^{-} \sin \frac{\alpha}{2}
\end{aligned}
$$




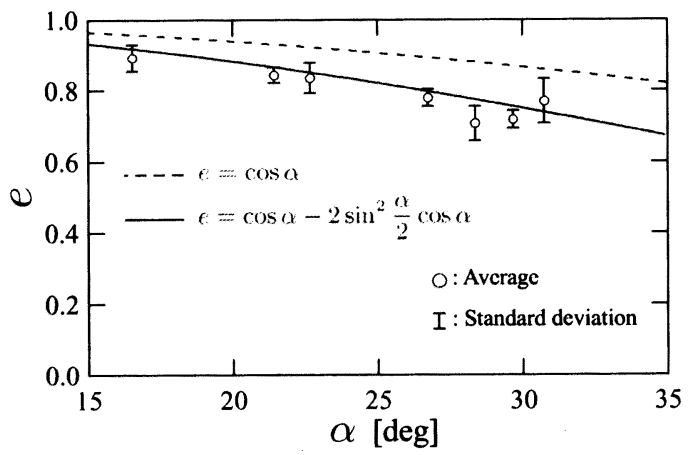

Fig. 7 Modified leg-exchange model

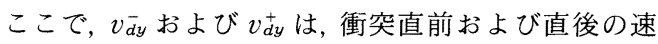
度の $y$ 方向成分を表す.また， $c$ は跳ね返り係数であ る. 式 (6)および式 ( 7 ) から, 衝突の衝撃によって発 生するトルクの総和は, 最終的に次のようになる.

$$
\int_{0}^{\Delta t_{d}} T \mathrm{~d} t \approx-2 M l^{2}(c+1) \dot{\theta}^{-} \sin ^{2} \frac{\alpha}{2}
$$

衝突前後の角運動量は, 次のような関係が成り立 つ.

$$
M l^{2} \dot{\theta}_{d}^{+}=M l^{2} \dot{\theta}^{-}+\int_{0}^{\Delta t_{d}} T \mathrm{~d} t
$$

ここで, $\dot{\theta}_{d}^{+}$は衝突直後の支持脚の角速度である.脚 切換えをモデル化する場合, 式 (9)に示す衝突の衝撃 による角運動量の損失を考慮しなければならない. 式 (8)および式 (9)から, $\dot{\theta}_{d}^{+}$は次のように与えられる.

$$
\dot{\theta}_{d}^{+}=\dot{\theta}^{-}-2(c+1) \dot{\theta}^{-} \sin ^{2} \frac{\alpha}{2}
$$

$4 \cdot 3$ 修正脚切換えモデル 本節では, $4 \cdot 2$ 節の結 果に基づき,より厳密な脚切換えモデルを導出する。 衝突直後と脚切換え直後において, 腰まわりの支持脚 の角運動量ならびに遊脚足先まわりの全角運動量が保 存されるものとする.これらの角運動量の保存則か ら, 次式が得られる。

$$
\dot{\boldsymbol{\theta}}^{+}=\boldsymbol{H}(\alpha) \dot{\boldsymbol{\theta}}_{d}^{+}
$$

ただし, $\dot{\boldsymbol{\theta}}_{d}^{+}\left(=\left[\dot{\theta}_{d}^{+}, \dot{\phi}_{d}^{+}\right]^{T}\right)$ は, 衝突直後の脚の角速度心゙ クトルを表す.式(11)から, 脚切換え後の支持脚およ び遊脚の角速度 $\dot{\theta}^{+}$および $\dot{\phi}^{+}$は, 次式のように導か れる。

$$
\begin{aligned}
\dot{\theta}^{+} & =\cos \alpha \dot{\theta}_{d}^{+} \ldots \ldots \ldots \ldots . \\
\dot{\phi}^{+} & =\cos \alpha(1-\cos \alpha) \dot{\theta}_{d}^{+} \\
& =(1-\cos \alpha) \dot{\theta}^{+}
\end{aligned}
$$

式(13) からわかるように, 脚切換え後の遊脚の角速度 $\dot{\phi}^{+}$は, 角速度 $\dot{\phi}_{d}^{+}$に関係しない.

式(10)および式 (12) から, 脚切換え直後の支持脚の 角速度は次のようになる。

$$
\dot{\theta}^{+}=\left[\cos \alpha-2(c+1) \sin ^{2} \frac{\alpha}{2} \cos \alpha\right] \dot{\theta}^{-}
$$

跳ね返り係数 $c$ が十分に小さい $(c \approx 0)$ ものとすると, 式(14) は次のように書き換えられる.

$$
\dot{\theta}^{+}=\left(\cos \alpha-2 \sin ^{2} \frac{\alpha}{2} \cos \alpha\right) \dot{\theta}^{-}
$$

なお, 着地時の股角度 $\alpha$ が十分に小さい場合は, 式 (15)の右辺第 2 項を無視することができ, 式 (4)と一 致する。

損失係数 $e$ の実験値ならびに式(15)による解析値 (実線)を図 7 に示す。図 7 からわかるように, 式(15) は近似度が高く, 修正脚切換えモデルは定量的にも妥 当なモデルといえる。

\section{5. 結言}

受動歩行の研究では, 平衡点の生成ならびにその安 定性あるいは安定化が非常に重要となっている(13)(14). 本研究では, 平衡点生成に大きく関与している脚切換 え現象について議論した。 以下に得られた結果をまと める.

（1）受動歩行機を模擬した簡単な実験機を用い て，一般的な脚切換えモデルを定性的・定量的に評価 した。その結果, 定性的には合っているが, 定量的に は問題があることを示した。

（2）脚切換えを引き起こす衝突現象は，実際，跳 ね返りは小さいものの弾性衝突である。また微小時 間, 支持脚足先まわりに衝突の衝撃力によるトルクが 発生し, 角運動量が損失する。

（3）力学的考察に基づいて定式化し，より厳密な 脚切換えモデル [式(15)］を導出した．損失係数に関 して高い近似度を示しており，修正モデルは定量的に も妥当なモデルといえる.

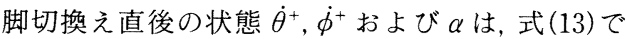
表される状態に拘束される。この点の実験的検証は今 後の課題である.

\section{文献}

(1) McGeer, T., Passive Dynamic Walking, The International Journal of Robotics Research, Vol.9, No.2 (1990), pp. 62-82.

(2) Osuka, K., Legged Robots and Control Scheme Based on a Sense of Passive Dynamic Walking, Journal of the Robotics Society of Japan, Vol. 20, No. 3 (2002), pp. 233-236.

(3) Collins, S. et al., Efficient Bipedal Robots Based on Passive-Dynamic Walkers, Science, Vol. 307 (2005), pp. 1082-1085.

(4) Ikemata, Y. et al., A Structure of the Mechanism of Stability of Fixed Points in Passive Walking, Journal of the Robotics Society of Japan, Vol. 23, No. 7 (2005), 
pp. 839-846.

( 5 ) Yamaguchi, J. et al., Stabilization of Biped Walking and Acquisition of Landing Surface Position Information Using Foot Mechanism with Shock Absorbing Material, Journal of the Robotics Society of Japan, Vol. 14, No. 1 (1996), pp. 67-74.

(6) Coleman, M. J. et al., Motions of a Rimless Spoked Wheel : a Simple $3 \mathrm{D}$ System with Impacts, The International Journal of Dynamics and Stability of Systems, Vol. 12, No. 3 (1997), pp. 139-160.

(7) Garcia, M. et al., The Simplest Walking Model: Stability, Complexity, and Scaling, Transaction of the ASME. Journal of Biomechanical Engineering, Vol. 120 (1998), pp. 281-288.

(8) Goswami, A. et al., A Study of the Passive Gait of a Compass-Like Biped Robot: Symmetry and Chaos, The International Journal of Robotics Research, Vol. 17, No. 12 (1998), pp. 1282-1301.

( 9 ) Asano, F. et al., Gait Generation and Control for Biped Robots Based on Passive Dynamic Walking, Journal of the Robotics Society of Japan, Vol. 22, No. 1 (2004), pp. 130-139.

(10) Wisse, M. et al., How to Keep From Falling Forward:
Elementary Swing Leg Action for Passive Dynamic Walkers, IEEE Transaction on Robotics, Vol. 21, No. 3 (2005), pp. 393-401.

(11) Spong, M. W. and Bullo, F., Controlled Symmetries and Passive Walking, IEEE Transaction on Automatic Control, Vol. 50, No. 7 (2005), pp. 1025-1031.

(12) Hurmuzlu, Y. and Chang, T., Rigid Body Collisions of a Special Class of Planar Kinematic Chains, IEEE Transaction on Systems, Man, and Cybernetics, Vol. 22, No. 5 (1992), pp. 964-971.

(13) Ikemata, Y. et al., A Gait Based on the Stability Mechanism of Passive Walking-Generation of Fixed Point and Local Stabilization Method-, Proceedings of 2005 JSME (The Japan Society of Mechanical Engineers) Annual Conference on Robotics and $\mathrm{Me}$ chatronics, (2005-6), 1 P 1-S-045.

(14) Ikemata, Y. et al., A Gait Based on the Stability Mechanism of Passive Walking-Global Stabilization Method and Experimental Test-, Proceedings of 2005 JSME (The Japan Society of Mechanical Engineers) Annual Conference on Robotics and Mechatronics, (2005-6), 1 P 2-S-040. 